\title{
Interpretation of the paranormal power like Extra Sensory Perception (ESP) and Psychokinesis (PK) through the consciousness model
}

\author{
Dhananjay Pal \\ Email address: \\ dhananjay.pal123@gmail.com,paldhananjay46@yahoo.com
}

Pharmacy College, Bengal School of Technology, Sugandha-Delhi Road, Chuchura, Dist.-Hooghly, West Bengal, INDIA, PIN-712 102

\section{To cite this article:}

Dhananjay Pal. Interpretation of the Paranormal Power Like Extra Sensory Perception (ESP) and Psychokinesis (PK) through the Consciousness Model. American Journal of Physics and Applications. Vol. 1, No. 3, 2013, pp. 80-90.

doi: 10.11648/j.ajpa.20130103.15

\begin{abstract}
A single field emerged at the origin of the universe, already containing within itself the blueprint of the physical universe. The primordial single field triggered the onset of the universe. Most physicists believe that a single super-force dominated the first instants of creation. Scientists have arrived at a simple but decisive conclusion that consciousness is very much a part of the universe, like other objects. Our consciousness model involving thought-carrying particle (TCP), thought retaining particle (TRP) and thought force (TF) signifies the existence of universal consciousness that exists along with the universe. This universal consciousness is a functional state of the universal mind (UM). This UM is evolved at the Big Bang from void. The UM is constituted by these TCP and TRP in the inherent presence of thought force (TF). Thought force (TF) is an expression of universal consciousness. The Thought force (TF) being the primordial quantum field functions as the original super-force. TF being the original super-force functions as the origin of all the fundamental fields. TCP is the carrier of thought force (TF) that, in turn, appears to be the origin of all the fields. The quantized energy $\left(\varepsilon_{T}\right)$ of TCP is responsible to cause the universal consciousness as well as the cosmic microwave background radiation temperature. The individual consciousness owes its origin to the universal consciousness created by the same $\varepsilon_{T}$. The same $\varepsilon_{T}$ is the energy responsible for generating thought force (TF). TF being an expression of the universal consciousness is applicable to any inanimate object as well as to any biological system (having thinking ability). The TF exerts its functions both in vitro and in vivo. We showed the existence of thought force in microcosm [TF (micro)] and thought force in macrocosm [TF (macro)]. This TF (micro) is theoretically found to be stronger than the strong nuclear force. TF (macro) is theoretically found to be weaker even than the gravitational force. These TCP, TRP, TF (micro), TF (macro), and the thought force (TF) in vitro and thought force (TF) in vivo play significant roles in understanding Extra Sensory Perception (ESP) and Psychokinesis (PK).
\end{abstract}

Keywords: Void, Cosmic Microwave Background Radiation (CMBR), Universal Mind (UM), Thought Force (TF), Though-Carrying Particle (TCP), Thought Retaining Particle (TRP), Quantized Energy $\left(\mathcal{E}_{T}\right)$ of TCP

\section{Introduction}

In Eastern philosophical traditions, consciousness is intrinsic to the universe, whereas in most Western views, consciousness is extrinsic, emerging from complex computation. How can these views be reconciled?

It is most relevant and important to indicate the names of various eminent physicists like Erwin Schrödinger, Eugene Wigner, Brian Josephson, John Wheeler, Roger Penrose, Henry P Stapp, Freeman J. Dyson, Paul Davies, David Bohm, Basil Hiley, Fritjof Capra, Fred Alan Wolf and Amit
Goswami who have addressed the inclusion of consciousness in their work. Consciousness is to be taken into account.

1.1. In contrast to the usual linear sequence of matter, body, life, brain, mind, consciousness, here the proposed cyclic sequence is first universal consciousness (a functional state of the universal mind), and then matter, body, life, brain, and regeneration of mind and consciousness. The evolution of life with mind and consciousness is possible purely due to the inherent existence of universal consciousness which exists along 
with the universe. The human nervous system is evolved to provide an appropriate material structure to individualize the universal consciousness, a characteristic of reality, pervading all manifestations.

Consciousness model of Pal et al [1-3] involving TCP, TRP and thought force $\left(\mathrm{T}_{\mathrm{F}}\right)$ signifies the existence of universal consciousness that exists along with the universe. Pal et al [3] showed that this universal consciousness is a functional state of Universal Mind (UM). Pal et al [3] explained that the UM is evolved at the Big Bang from the eternal Void. This Void, in turn, is the source of infinite energy. And this $\mathrm{UM}$ is a finer matter. The individual mind being a constituent of the UM is also a finer matter. The constituents of the UM and individual mind are the same. The ultimate constituents of matter and mind are the same as both mind and matter are aspects of one fundamental reality, which is called UM. The brain is the mediating link or interface between the individual mind and body.

Pal et al [3] explained that the constituents of the UM are the ultimate constituents of matter itself as everything in this universe is a manifestation of this UM. Pal et al [3] expressed that the UM is constituted by these TCP and TRP in the inherent presence of thought force $\left(\mathrm{T}_{\mathrm{F}}\right)$. Pal et al $[1,3]$ further explained that the ultimate constituents of matter and mind are these TCP and TRP in the inherent presence of thought force $\left(\mathrm{T}_{\mathrm{F}}\right)$ in vitro and thought force $\left(\mathrm{T}_{\mathrm{F}}\right)$ in vivo.

Physicists determined that underlying quantum fields give birth to elementary particles. Bhaumik [4] mentioned that Frank Wilczek pointed out, "In quantum field theory, the primary elements of reality are not individual particles, but underlying fields. Thus, for example, all electrons are but excitations of an underlying field, naturally called electric field". The same holds true for all the fundamental particles of which matter is made.

The existence of matter depends on the existence of force and vice versa. TCP cannot exist without TRP and vice versa. Many physicists believe that unifying all the forces, including gravity, into a single theory would require a phenomenon called super-symmetry. With supersymmetry, every fermion would have a boson twin, and vice-versa. The thought force $\left(\mathrm{T}_{\mathrm{F}}\right)$ is carried by the TCP in the presence of its super-symmetrical partner TRP. TCP that behaves like boson should accompany its supersymmetrical partner TRP that functions like fermion in the generalized simpler way. It is to be noted that these TCP and TRP function like wavicle: wave-particle duality.

\section{Thought Force}

Pal et al [1,3] and Pal [5] explained the existence of thought force $\left(\mathrm{T}_{\mathrm{F}}\right)$. Thought force $\left(\mathrm{T}_{\mathrm{F}}\right)$, an expression of the universal consciousness, is the primordial quantum field that, in turn, functions as the primary unified field. This $T_{F}$ being an expression of the universal consciousness is applicable to any inanimate object as well as to any biological system (having thinking ability). Thus the $\mathrm{T}_{\mathrm{F}}$ being an expression of the universal consciousness exerts its functions both in vitro and in vivo.

Physicists determined that underlying quantum fields give birth to elementary particles. Pal [5] expressed that the thought force $\left(\mathrm{T}_{\mathrm{F}}\right)$ is the primordial quantum field. Thought force $\left(\mathrm{T}_{\mathrm{F}}\right)$ being the primordial quantum field functions as the primary unified field. Thought force $\left(T_{F}\right)$ being the primordial quantum field gives birth to TRP that appears to be the origin of all the matter particles. TCP is the carrier of thought force $\left(\mathrm{T}_{\mathrm{F}}\right)$ that, in turn, appears to be the origin of all the fields. TCP thus appears to be the origin of all the field particles.

In a purpose to involve both the non-living and living systems of the world, Pal [5] has shown the existences of these TCP, TRP and thought force $\left(\mathrm{T}_{\mathrm{F}}\right)$ in vitro and thought force $\left(\mathrm{T}_{\mathrm{F}}\right)$ in vivo. Anyone can call this TCP by any other name, but as the highly developed living system will have to be evolved in the universe in the long run and as the thought of highly developed living system appears to be a kind of force to be called the thought force $\left(\mathrm{T}_{\mathrm{F}}\right)$ in vivo, we considered it is wise to call it as TCP. Further, as the universe exists along with the universal consciousness that, in turn, is created by the quantized energy $\left(\varepsilon_{T}\right)$ of TCP, we had to use the term TCP.

Pal (5) expressed that the non-living system of the world is governed by the thought force $\left(\mathrm{T}_{\mathrm{F}}\right)$ in vitro and this Thought force $\left(\mathrm{T}_{\mathrm{F}}\right)$ in vitro gives rise to $\mathrm{T}_{\mathrm{F}}$ (micro), SNF, EMF, WNF, GF and $\mathrm{T}_{\mathrm{F}}$ (macro) where $\mathrm{T}_{\mathrm{F}}$ (micro) $=$ Thought force in microcosm, SNF = Strong nuclear force, $\mathrm{EMF}=$ Electromagnetic force, $\mathrm{WNF}=$ Weak nuclear force, $\mathrm{GF}=$ Gravitational force and $\mathrm{T}_{\mathrm{F}}(\mathrm{macro})=$ Thought force in macrocosm. It is to be noted here that $\mathrm{T}_{\mathrm{F}}$ (micro) is a stronger force than the SNF and $\mathrm{T}_{\mathrm{F}}$ (macro) is a weaker force even than the GF.

Pal (5) also expressed that the living system of the world is governed by the thought force $\left(\mathrm{T}_{\mathrm{F}}\right)$ in vivo and this Thought force $\left(\mathrm{T}_{\mathrm{F}}\right)$ in vivo is a type of force that represents the biological 'thought' which is the action of mind. This 'thought' being a type of force controls the 'thought processes' involving the firing of neurons through the quantum mechanical activities of these TCP and TRP in the presence of consciousness. Consciousness in living organisms is a process which involves the quantum mechanical activities of these TCP and TRP, the ultimate constituents of any matter as well as any mind in the inherent presence of thought force $\left(\mathrm{T}_{\mathrm{F}}\right)$ in vitro and the thought force $\left(\mathrm{T}_{\mathrm{F}}\right)$ in vivo as indicated by Pal et al [3]. This consciousness, in turn, is the quantized energy $\left(\varepsilon_{T}\right)$ of TCP. The thought force $\left(\mathrm{T}_{\mathrm{F}}\right)$ in vivo is demonstrated in numerous experiments in which thought has an effect on a physical process (often known as mind over matter). This biological 'thought' is a type of force that can cause movement. Controlling movement through thought alone is observed in several experiments conducted by many scientists as indicated by Pal (5). These experiments thus signify the existence of thought force $\left(\mathrm{T}_{\mathrm{F}}\right)$ in vivo.

Pal [5] explained the existence of $\mathrm{T}_{\mathrm{F}}$ (micro) (= Thought force in microcosm). This $\mathrm{T}_{\mathrm{F}}$ (micro) is the strongest 
interaction (a new class of 'extra strong' interaction). It is stronger than SNF (Strong Nuclear Force).

Pal [5] has also shown the existence of $\mathrm{T}_{\mathrm{F}}$ (macro) (= Thought force in macrocosm). It is the "weakest force" which is much weaker even than the gravity.

2.1. Pal et al [3] developed three different equations expressing the quantized energy ( $\boldsymbol{\varepsilon}_{T}$ ) of TCP. The value of $\mathcal{E}_{T}$ in one of the three equations is shown below:

$$
\mathcal{E}_{T}=4.384 \times 10^{-16} \mathrm{erg} \equiv 2.73 \times 10^{-4} \mathrm{eV} \equiv 2.73 \mathrm{~K} \cong C M B R \text { temperature } \equiv 2.725 \mathrm{~K} .
$$

This conversion of erg $\equiv \mathrm{eV} \equiv \mathrm{K}$ is given by Weisskopf [6] as follows:

$$
1 \mathrm{erg} \cong 0.6241807 \times 10^{12} \mathrm{eV} \text { and } 10^{-4} \mathrm{eV} \cong 1 \mathrm{~K}
$$

2.2. Pal et al [3] expressed that the CMBR temperature is due to $\varepsilon_{T}$, the quantized energy of TCP where

$$
\varepsilon_{T}=4.384 \times 10^{-16} \mathrm{erg} \equiv 2.73 \times 10^{-4} \mathrm{eV} \equiv 2.73 \mathrm{~K} \cong C M B R \text { temperature } \equiv 2.725 \mathrm{~K} .
$$

As per Pal et al [3], it is interesting to note that all of the three different equations ultimately give rise to the same result that is equivalent to the CMBR temperature. A sort of relationship is thus observed between the $\varepsilon_{T}$ and the CMBR temperature. This coincidence is thus signifying a probable role of TCP on the maintenance of CMBR temperature. Further, this coincidence is also signifying the existence of these TCP in the presence of TRP. TCP cannot exist without TRP and vice versa. The presence of TCP, TRP and Thought force $\left(\mathrm{T}_{\mathrm{F}}\right)$ in the universe is thus indicated and expressed mathematically. At present we are unable to explain when and how these TCP and TRP decoupled from the primordial cosmic soup.

Pal et al $[1,3]$ showed that the quantized energy $\left(\varepsilon_{T}\right)$ of TCP is responsible to cause the universal consciousness as well as the cosmic microwave background radiation temperature. The individual consciousness owes its origin to the universal consciousness created by the same $\varepsilon_{T}$. Ultimately this $\mathcal{E}_{T}$ represents universal consciousness. The existence of CMBR temperature indicates the existence of the TCP in the presence of TRP. The existence of TCP ensures the existence of the thought force $\left(\mathrm{T}_{\mathrm{F}}\right)$. Further, this $\mathrm{T}_{\mathrm{F}}$ being an expression of the quantized energy $\left(\boldsymbol{\varepsilon}_{T}\right)$ of TCP exerts its functions both in vitro and in vivo.

\section{What Is Life}

Life is a state of flux that is being maintained by a typical form of energy which is nothing but the consciousness itself. Pal et al [3] and Pal [7] showed that the quantized energy $\left(\varepsilon_{T}\right)$ of TCP is responsible to cause the universal consciousness as well as the cosmic microwave background radiation temperature. The individual consciousness owes its origin to the universal consciousness created by the same $\varepsilon_{T}$. Pal et al $[1,3]$ and Pal [7] explained that life may be defined as a state of functional manifestation of consciousness that, in turn, is the quantized energy ( $\varepsilon_{T}$ ) of TCP. This $\mathcal{E}_{T}$ represents universal consciousness.

Thus,

$$
\text { Life }=\mathrm{f}(\text { Consciousness })=\mathrm{f}\left(\boldsymbol{\varepsilon}_{T}\right)
$$

where $\varepsilon_{T}=$ quantized energy of the TCP $=4.384 \times 10^{-16} \mathrm{erg}$.

$$
\varepsilon_{T}=h v_{T}=h c / \lambda_{T}=4.384 \times 10^{-16} \mathrm{erg}
$$

where

$\mathcal{E}_{T}=$ quantized energy of the TCP $=4.384 \times 10^{-16} \mathrm{erg}$,

$\boldsymbol{v}_{T}=$ frequency of the TCP

$=\varepsilon_{T} / h=66.12 \times 10^{9} \mathrm{~Hz} .=66.12 \mathrm{GHz}$,

$\mathrm{h}=$ Planck's quantum constant $=6.63 \times 10^{-27} \mathrm{erg} . \mathrm{sec}$,

$\mathrm{c}=$ free-space velocity of light $=3 \times 10^{10} \mathrm{~cm} / \mathrm{sec}$,

$\lambda_{T}=$ wave-length of the $\mathrm{TCP}=0.4537 \mathrm{~cm}$.

\subsection{What Is Consciousness}

Psychologists, neuroscientists, philosophers, and other professionals continue to engage in an ongoing debate as to what consciousness means. In reality, we may never know. Is it a product of the biological and classical physical interactions of the human brain; or is it something more fundamental, perhaps electromagnetic, or the result of quantum physics principles that we don't yet fully understand? Could it be something even more profound than that -- something beyond the scope of science and physics, any kind of physics, for us to understand?

According to the ancient Vedanta, consciousness is not an emergent property of matter that comes into existence only through the functioning of the human nervous system. Instead, consciousness is a characteristic of reality, pervading all manifestations. This unbounded field of nature's universal consciousness is not limited to an individual consciousness. From this viewpoint, the role of the human nervous system is to provide an appropriate material structure to individualize the universal consciousness. It appears that inanimate matter itself cannot 
generate consciousness without the inherent existence of universal consciousness.

Pal et al [2] explained, "Consciousness is the realization of existence, and there are as many states of consciousness as there are states of existence. Every living being has a consciousness of its own depending on complexity of the brain and the activity of the viable numbers of TCP in the presence of TRP; and the state of its consciousness changes every moment of time. Consciousness is the perception of the relation it bears to things and as this relation changes, consciousness changes its character. Consciousness itself does not change; it only moves up and down on the 'scale of the realization' of existence through the 'sub-conscious', 'conscious' and 'super-conscious' states". There is another term called unconscious state. The most usual unconscious state is sleep. A deeper form of unconsciousness is called a coma.

\subsection{Possible Relation of Consciousness with Mind: Possible Relation of Animate with Inanimate Through Consciousness}

Modern scientists have not even been able to arrive at a consensus on what should be a definition of the totality of consciousness. The brain is intricately linked to the process of consciousness and consciousness is thought to be a phenomenon of the mind.

It appears that

$$
\text { Consciousness }=\mathrm{f}(\operatorname{mind})
$$

Consciousness is the functional state of mind. Presence of consciousness signifies the presence of mind and vice versa.

It is apparent that

$$
\text { Animate } \neq \text { Inanimate }
$$

Three critical factors which distinguish life from nonliving are consciousness, metabolism and reproduction. (4):

In a gross presentation, we can express from the equation

$$
\text { Animate }- \text { Consciousness }=\text { Inanimate }
$$

Scientists would have to define and characterize consciousness properly. We should have the proper knowledge about the exact characteristics of consciousness in order to address many present day scientific enigmas.

\subsection{Consciousness may be Defined as the 'Self-Organized' Capability of any Living being to Activate TCP and TRP}

Pal et al [3] expressed that consciousness may be defined as the 'self-organized' capability of any living being to activate TCP and TRP, the ultimate constituents of mind and matter and to exert its functions. What can generate, maintain and activate TCP and TRP is called animate having 'active consciousness' and what cannot is called inanimate, i.e., devoid of active consciousness. As anything inanimate does neither have the power to activate the TCP and TRP nor have the capability to catalyze the activity of TCP and TRP, so it cannot generate consciousness. On the contrary, anything animate has the 'self-organized' power to generate, activate and catalyze the activity of TCP and TRP in order to generate and maintain consciousness along with the vital living force. Prigogine et al [8] explained "Self-Organization in Non-Equilibrium Systems".

Consciousness in living organisms is a process which involves the quantum mechanical activities of these TCP and TRP, the ultimate constituents of any matter as well as any mind in the inherent presence of thought force $\left(\mathrm{T}_{\mathrm{F}}\right)$ in vitro and the thought force $\left(\mathrm{T}_{\mathrm{F}}\right)$ in vivo as indicated by Pal et al [1, 3]. And these TCP and TRP govern the activities of neurons (not the other way round). Neurons are simply the equipments used to generate consciousness and awareness. The consciousness itself is functioning as an inter-linking agent between the animate and inanimate through the quantum mechanical activities of these TCP and TRP indicated by [3].

\section{Existence of Universal Consciousness}

Pal et al [3] and Pal [7] showed the existence of universal consciousness and explained that the quantized energy $\left(\varepsilon_{T}\right)$ of TCP is responsible to cause the universal consciousness as well as the cosmic microwave background radiation temperature. The individual consciousness owes its origin to the universal consciousness created by the same $\varepsilon_{T}$.Many physicists agree with the idea that consciousness is non-local, fundamental in the universe and consciousness is very much a part of the universe, like other objects. It is to be noted that $\varepsilon_{T}$, the quantized energy of TCP represents universal consciousness.

Nelson [9], Director of Global Consciousness Project, has observed through the experimentation that coherent consciousness creates order in the world; and subtle interactions link us with each other and the Earth. When human consciousness becomes coherent and synchronized, the behavior of random systems may change. Quantum event based random number generators (RNGs) produce completely unpredictable sequences of zeroes and ones. But when a great event synchronizes the feelings of millions of people, our network of RNGs becomes subtly structured. The probability is less than one in a billion that the effect is due to chance. The evidence suggests an emerging noosphere, or the unifying field of consciousness described by sages in all cultures. This evidence signifies and proves the existence of universal consciousness.

The existence of universal consciousness is explained by Radin [10] through experimentation as it is expressed in his book The Conscious Universe: The Scientific Truth of Psychic Phenomena. Further, Consciousness, not matter, is the ground of all existence, declares University of Oregon physicist Goswami through his published (1993) book, 
"The Self-Aware Universe: How Consciousness Creates the Material World".

As per Penrose [11], consciousness is a part of the universe. Van De Bogart [12] explained, "Since consciousness is a part of the universe it then follows that all consciousness, and the universe, are of the same matrix of energy fields".

Pal et al [3] and Pal [7] explained that the universe exists along with the universal consciousness. This universal consciousness exists throughout the universe in the form of universe wide web $(u w w)$ covering fields, particles, space-time continuum, dark matter, dark energy, void and all its known and unknown parameters along with all its inhabitants (with or without consciousness). The quantized energy $\left(\boldsymbol{\varepsilon}_{T}\right)$ of TCP represents universal consciousness. This universal consciousness is to be taken into account, but usually ignored.

\section{What is the Exact Definition of Mind? What is Mind?}

We observe a great controversy concerning the exact definition of mind. There are two apparently opposite views: one is the substantial view and the other is the functional view.

In the substantial view, the mind is a type of substance. Mind is a finer matter having an autonomous existence. Mind is a single entity, perhaps having its base in the brain but distinct from it. In its most extreme form as in the Indian Upanishads and Vedanta, the mind is not only a finer matter but also it is an entity wholly separate from the body, in fact a manifestation of the soul, which will survive the body's death in the form of the spiritual body or mental body [called Linga Sharira or Sukshma Sharira in Sanskrit] as expressed by Vivekananda [13] who indicated that this mental body bears all the mental impressions. This mental body is also called 'spirit'.

In the functional view, the mind is closely related to the functions of the brain and can have no autonomous existence beyond the brain, nor can they survive its death. In this view, mind is a 'state' created by the activities of the brain with other parts of the nervous system as it is indicated by cognitive neuro-scientists and Artificial Intelligence (AI) scientists. According to them 'minds are simply what brains do'. In this functional view, mind is a subjective manifestation of consciousness: the human brain's ability to be aware of its own existence. The concept of the mind is therefore a means by which the conscious brain understands its own operations.

The modern cognitive neuroscientists generally accept the fact that the "mind" is not an isolated entity and the mind is a state created by the activities of brain with other parts of the nervous system (CNS, PNS along with ANS). Although the mind is generally accepted to be an abstract having no spatial location or public observability, yet it is a type of fine matter according to the ancient Indian Upanishads and Vedanta. The Vedanta indicates that the universe exists along with the universal consciousness. This universal consciousness is a functional state of the Universal Mind. Pal et al [1, 3] explained that any matter as well as any individual mind is constituted by these TCP and TRP in the inherent presence of Thought force $\left(\mathrm{T}_{\mathrm{F}}\right)$ in vitro and Thought force $\left(\mathrm{T}_{\mathrm{F}}\right)$ in vivo.

Modern Scientists are not yet able to understand how the brain works to make the mind. They know that brain has got neurons that communicate across synapses by releasing a neurotransmitter, and that generates electrical impulses, and the receiving neuron then talks to its neighbor neurons the same way. If the mind depends on the brain, then all aspects of the mind are going to depend on these simple electrical, chemical processes. According to this concept, the existence of the UM requires the existence of the universal brain to form the UM. The concept of universal brain is not logically acceptable. Thus the concept that the mind depends on the brain becomes questionable if the existence of the UM is valid.

5.1. It appears that scientists would have to decide in a purpose to conclude clearly whether mind is a 'state' (created by the activities of the brain with other parts of the nervous system as it is indicated by the functional view of mind) or 'a finer matter' (as it is indicated by the Indian Upanishads and Vedanta).

\section{Special Characteristics of mind and Consciousness}

1 The basic mystery of the mind is how does it emerge from pure matter? How do those units that are made of tiny particles, give rise to the unique and essentially private, experience called consciousness? Do the particles that constitute our brain determine what we think and do? Do these tiny particles ultimately govern the thinking ability of the bioelectrical system? Or, are we free to have our own will? Is consciousness just froth sitting on top of the brain's electronics? How consciousness is being operated? Why should a bunch of atoms have thinking ability? Gross answers to all these inquiries are possible if we accept these TCP and TRP as the ultimate constituents of mind and matter in the inherent presence of thought force $\left(\mathrm{T}_{\mathrm{F}}\right)$ in vivo and thought force $\left(\mathrm{T}_{\mathrm{F}}\right)$ in vitro as indicated by Pal et al [3]. It is to be noted that the thought force $\left(\mathrm{T}_{\mathrm{F}}\right)$ being a primordial quantum field exerts its functions both in vitro and in vivo.

2 Modern Scientists are not yet able to understand how the brain works to make the mind. They know that brain has got neurons that communicate across synapses by releasing a neurotransmitter, and that generates electrical impulses, and the receiving neuron then talks to its neighbors the same way. If the mind depends on the brain, then all aspects of the mind are going to depend on these simple electrical, chemical processes. According to this concept, the existence of 
the UM requires the existence of the universal brain to form the UM. The concept of universal brain is not logically acceptable. Thus the concept that the mind depends on the brain becomes questionable if the existence of the UM is valid.

3 We are what our minds make us. The mind is a very powerful controller of the body. The mind controls everything as indicated by $\mathrm{Pal}$ et al [1,3] and Pal [7]. Mind is conditioned from the time we are young. It gives our abilities, our perceptions, our character and the way we think. From science to religion, from politics to economics, everything is controlled by the human mind. We perceive, we believe and we react. Things that matter are what we think they are. The quest for truth is bafflingly elusive, after all what is the 'truth'? We have come to the realization that if I believe it is true, it indeed is true for me, regardless of how incredible you may think it is. Experiments do not matter, arguments do not matter, reality does not matter, in fact, matter does not matter---it is all in the mind. As a joker succinctly put it, "It is a case of mind over matter-I do not mind and you do not matter".

4 Consciousness model of Pal et al [1-3] involving TCP, TRP and thought force $\left(\mathrm{T}_{\mathrm{F}}\right)$ signifies the existence of universal consciousness that exists along with the universe. Pal et al [3] showed that this universal consciousness is a functional state of Universal Mind (UM). Pal et al [3] explained that the UM is evolved at the Big Bang from the eternal Void. This Void, in turn, is the source of infinite energy. And this UM is a finer matter. The individual mind being a constituent of the UM is also a finer matter. The constituents of the UM and individual mind are the same. The ultimate constituents of matter and mind are the same as both mind and matter are aspects of one fundamental reality, which is called UM. The brain is the mediating link or interface between the individual mind and body. Pal et al [3] explained that the constituents of the UM are the ultimate constituents of matter itself as everything in this universe is a manifestation of this UM. Pal et al [3] expressed that the UM is constituted by these TCP and TRP in the inherent presence of thought force $\left(\mathrm{T}_{\mathrm{F}}\right)$. Pal et al $[1,3]$ further explained that the ultimate constituents of matter and mind are these TCP and TRP in the inherent presence of thought force $\left(\mathrm{T}_{\mathrm{F}}\right)$ in vitro and thought force $\left(\mathrm{T}_{\mathrm{F}}\right)$ in vivo.

5 Current scientific views regarding the origin of consciousness vary widely and range from an 'epiphenomenon' arising from neuronal networks, to neuronal quantum processes, to a separate undiscovered scientific entity.

6 Consciousness is the functional state of mind. Presence of consciousness signifies the presence of mind and vice versa. It is to be understood that consciousness is the realization of existence and consciousness moves up and down on the 'scale of the realization' of existence through the 'sub-conscious', 'conscious' and 'super-conscious' states as indicated by Pal et al [2].

7 Consciousness may be defined as the 'self-organized' capability of any living being to activate TCP and TRP, the ultimate constituents of mind and matter and to exert its functions. What can generate, maintain and activate TCP and TRP is called animate having 'active consciousness' and what cannot is called inanimate, i.e., devoid of active consciousness.

8 Continuity of consciousness is found through the experimental observations of Parnia[14], Lommel [15], Fenwick [16] and Beauregard \& O'Leary [17 \& 18] and demonstrate the existence of consciousness during the cessation of brain activity and thus support the existence of universal consciousness as well as substantial view of mind as indicated by the Indian Upanishads and Vedanta.

9 Everything in this universe is interlinked and intertwined through the existence of the quantum mechanical activities of these TCP in the inherent presence of TRP. Pal et al [1,3] showed that the quantized energy $\left(\varepsilon_{T}\right)$ of TCP is responsible to cause the universal consciousness as well as the cosmic microwave background radiation temperature. The individual consciousness owes its origin to the universal consciousness created by the same $\varepsilon_{T}$. Ultimately this $\varepsilon_{T}$ represents universal consciousness. This universal consciousness functions as a universe wide web (uww) covering the universe as a whole with all its parameters (including void) and inhabitants (with or without consciousness). In this picture, uww of consciousness, quantum concepts like wave particle dualism, position momentum uncertainty, nonlocality and concept of unified field become somewhat understandable as all the entities of this universe are interlinked and intertwined. In this picture, the universal consciousness replaces ether of yesteryears and contains the whole of the universe in its fold. The 'spooky action-at-a-distance' may thus be built in nature through the existence of these TCP and TRP in the presence of thought force $\left(\mathrm{T}_{\mathrm{F}}\right)$.

10 In a purpose to conclude clearly, it appears, that scientists would have to decide whether mind is a 'state' (created by the activities of the brain with other parts of the nervous system as it is indicated by the functional view of mind) or 'a finer matter' (as it is indicated by the Indian Upanishads and Vedanta).

\section{Psi (Parapsychology) and the Related Terminologies}

$P_{s i}$ is a term from parapsychology derived from the Greek, $\psi$ psi, 23rd letter of the Greek alphabet; from the

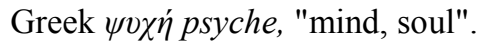




\section{Types of Parapsychology}

The phenomena in question fall into two broad groups:

1 Extra-sensory perception (also known as anomalous cognition)

\section{Anomalous operation}

Extra-sensory perception includes telepathy, clairvoyance, clairaudience, clairalience, clairgustance and precognition.

Anomalous operation includes psychokinesis (in the past referred to as telekinesis), out-of-body experiences (OBE), near-death experiences (NDE), mediumship and reincarnation.

The general term "psi phenomena" (or the somewhat older term, "psychic phenomena") cover all of these psychic phenomena.

Parapsychology is the scientific study of paranormal psychic phenomena, including ESP (Extra-Sensory Perception). Parapsychologists generally regard such tests as the ganzfeld experiment as providing compelling evidence for the existence of ESP. The consensus of the Parapsychological Association is that certain types of psychic phenomena such as psychokinesis, telepathy, and astral projection are well established.

\section{Extrasensory Perception (ESP)}

Extrasensory perception (ESP) involves reception of information not gained through the recognized physical senses but sensed with the mind. The term was adopted by psychologists to denote psychic abilities such as telepathy, clairaudience, and clairvoyance, and their trans-temporal operation as precognition or retrocognition. ESP is also sometimes casually referred to as a sixth sense, gut instinct or hunch. The term implies acquisition of information by means external to the basic limiting assumptions of science, such as that organisms can only receive information from the past to the present.

The scientific community rejects ESP due to the absence of an evidence base, the lack of a theory which would explain ESP, and the lack of experimental techniques which can provide reliably positive results as indicated by Radin [19], and Carroll [20].

\section{Psychokinesis and Telekinesis}

The term psychokinesis (literally "mind-movement"), also referred to as telekinesis (Greek, literally "distantmovement") with respect to strictly describing movement of matter, sometimes abbreviated as PK and TK respectively. They are used to refer to the direct influence of mind on a physical system that cannot be entirely accounted for by the mediation of any known physical energy (i.e. moving objects with the mind). Examples of psychokinesis could include distorting or moving an object, and influencing the output of a random number generator indicated by Jeffers [21].
Psychokinesis is the umbrella term for various related specialty abilities, which may include:

1 Telekinesis: movement of matter at the micro or macro (visible objects, life forms, etc.) levels. One can move, lift, agitate, vibrate, spin, bend, break, or can cause impact through telekinesis).

2 Speed up or slow down the naturally occurring vibrations of atoms in matter to alter temperature indicated by Kakalios [22], possibly to the point of ignition if combustible (also known as pyrokinesis when speeding up vibrations, and cryokinesis when slowing them down) indicated by Genzmer et al [23].

3 Self levitation (rising in the air unsupported, flying) indicated by Time-Life Books [24].

4 Influencing events (sports, gambling, election, prolongation of life, etc.) indicated by Time-Life Books [24].

5 Biological healing indicated by Hathaway [25].

6 Teleportation (disappearing and reappearing elsewhere) indicated by Mish [26].

7 Phasing through matter indicated by Time-Life Books [24].

8 Electro-psychokinesis, the ability to control any and all electrical, electronic, or electro-mechanical devices such as computers, elevators, FAX machines, etc.

9 Transmutation of matter indicated by Time-Life Books [24] and Colman [27].

10 Metamorphosis Shape-shifting indicated by Cavendish and Innes [28].

11 Energy shield (force field) indicated by Mass Media Funk [29].

12 Control of magnetism indicated by Time-Life Books [24].

13 Control of photons (light waves/particles) indicated by Bersani and Martelli [30].

14 14. Thoughtform projection or telepathic projection (a physically perceived person, animal, creature, object, ghostly entity, etc., created in the mind and projected into three-dimensional space and observable by others).

15 Thoughtography indicated by McCoy [31] (Nensha in Simplified Chinese, sence inception), better known to English speakers as thoughtography or projected thermography or nengraphy, is the ability to psychically "burn" images from one's mind onto surfaces, or even into the minds of others.

Both Telekinesis and Psychokinesis concepts have been described by other terms, such as "remote influencing", "distant influencing" "remote mental influence", "distant mental influence", "directed conscious intention", "anomalous perturbation", and "mind over matter".

As research entered the modern era, it became clear that many different, but related, abilities could be attributed to the wider description of psychokinesis and these, along with telekinesis, are now regarded as the specialties of PK. "Telekinesis is a form of PK" indicated by Davis [32]. Psychokinesis is the general term that can be used to 
describe a variety of complex mental force phenomena (including object movement) and telekinesis is used to refer only to the movement of objects, however tiny (a grain of salt, or air molecules to create wind) indicated by Guiley [33] or large (an automobile, building, or bridge).

Micro-PK (also micro-TK) is a very small effect, such as the manipulation of molecules, atoms, subatomic particles etc. indicated by Broughton [34] that can only be observed with scientific equipment. The words are abbreviations for micro-psychokinesis indicated by Guiley [33] and microtelekinesis. Macro-PK (also macro-TK) is a large-scale effect that can be seen with the unaided eye. The adjective phrases "microscopic-scale," "macroscopic- scale," "smallscale," and "large-scale" may also be used; for example, "a small-scale PK effect."

\section{Direct Mental Interactions with Living Systems (DMILS)}

Formerly called bio-PK, "direct mental interactions with living systems" (DMILS) studies the effects of one person's intentions on a distant person's psychophysiological state. One type of DMILS experiment looks at the commonly reported "feeling of being stared at." The "starer" and the "staree" are isolated in different locations, and the starer is periodically asked to simply gaze at the staree via closed circuit video links. Meanwhile, the staree's nervous system activity is automatically and continuously monitored.

Parapsychologists have interpreted the cumulative data on this and similar DMILS experiments to suggest that one person's attention directed towards a remote, isolated person can significantly activate or calm that person's nervous system. In a meta-analysis of these experiments published in the British Journal of Psychology in 2004, researchers found that there was a small but significant

\section{Ganzfeld (German for "Whole Field")}

The Ganzfeld (German for "whole field") is a technique used to test individuals for telepathy. The technique - a form of moderate sensory deprivation - was developed to quickly quiet mental "noise" by providing mild, unpatterned stimuli to the visual and auditory senses.

In the typical Ganzfeld experiment, a "sender" and a "receiver" are isolated indicated by Hyman Ray [35]. The receiver is put into the Ganzfeld state indicated by Radin [36] or Ganzfeld effect and the sender is shown a video clip or still picture and asked to mentally send that image to the receiver. The receiver, while in the Ganzfeld, is asked to continuously speak aloud all mental processes, including images, thoughts, and feelings. At the end of the sending period, typically about 20 to 40 minutes in length, the receiver is taken out of the Ganzfeld state and shown four images or videos, one of which is the true target and three of which are non-target decoys. The receiver attempts to select the true target, using perceptions experienced during the Ganzfeld state as clues to what the mentally "sent" image might have been.

Some parapsychologists have claimed that the aggregate results of ganzfeld experiments indicate that, on average, the target image is selected by the receiver more often than would be expected by chance alone; these claims have been summarized by parapsychologist Radin [36] in his book The Conscious Universe.

\section{TCP and TRP in the Inherent Presence of Thought Force (TF) in Vitro and the Thought Force (TF) in Vivo Play Significant Roles in Paranormal Phenomena Like Extra Sensory Perception (ESP) and Psychokinesis (PK)}

Our consciousness model involving TCP and TRP in the inherent presence of thought force $\left(\mathrm{T}_{\mathrm{F}}\right)$ in vitro and the thought force $\left(\mathrm{T}_{\mathrm{F}}\right)$ in vivo provides significant guidelines to explain paranormal phenomena like Extra Sensory Perception (ESP) and Psychokinesis (PK).

Pal et al [3] explained that everything in this universe is interlinked and intertwined through the existence of the quantum mechanical activities of these TCP in the inherent presence of TRP. The quantized energy $\left(\mathcal{E}_{T}\right)$ of TCP represents universal consciousness. This consciousness functions as a universe wide web (uww) covering the universe as a whole with all its parameters (including void) and inhabitants (with or without consciousness). In this picture, uww of consciousness, quantum concepts like wave particle dualism, position momentum uncertainty, nonlocality and concept of unified field become somewhat understandable as all the entities of this universe are interlinked and intertwined. In this picture, the universal consciousness replaces ether of yesteryears and contains the whole of the universe in its fold. The 'spooky action-ata-distance' may thus be built in nature through the existence of these TCP and TRP in the presence of thought force (TF) in vitro and thought force (TF) in vivo.

Pal et al [3] also expressed that these TCP and TRP are the ultimate constituents of matter and mind in the inherent presence of thought force $\left(\mathrm{T}_{\mathrm{F}}\right)$ in vitro and thought force $\left(\mathrm{T}_{\mathrm{F}}\right)$ in vivo. Thus these TCP and TRP being the ultimate constituents of mind as well as matter play the most significant roles not only in the telepathy and 'psychokinesis' (PK) but also in the exercise of other paranormal power. Many modern scientists think that a time will come when they would be able to develop the desired computer with intelligence having consciousness which would interact as intelligently as any human on any subject. The key to this new direction lies in the research of biological, mental and spiritual phenomena such as psychic phenomena ("Psi") and other psychic powers that have 
been overlooked by modern scientists.

\section{TCP and TRP Play the Significant Roles in the So-Called 'Non- Locality' Problem in Quantum Mechanics}

Everything in this universe is interlinked and intertwined through the existence of the quantum mechanical activities of these TCP in the presence of TRP.

The entire Universe or the particles in it are 'connected' through the existence of the quantum mechanical activities of these TCP in the presence of TRP. Pal et al [3] showed that the quantized energy $\left(\varepsilon_{T}\right)$ of TCP is responsible to cause the universal consciousness as well as the cosmic microwave background radiation temperature. The individual consciousness owes its origin to the universal consciousness created by the same $\varepsilon_{T}$. This universal consciousness functions as a universe wide web (uww) covering the universe as a whole with all its parameters (including void) and inhabitants (with or without consciousness). In this picture, uww of consciousness, quantum concepts like wave particle dualism, position momentum uncertainty, nonlocality and concept of unified field become somewhat understandable as all the entities of this universe are interlinked and intertwined. In this picture, the universal consciousness replaces ether of yesteryears and contains the whole of the universe in its fold.

The 'spooky action-at-a-distance' is thus built in nature through the existence of the quantum mechanical activities of these TCP in the inherent presence of TRP. The spooky non-local correlations-at-a-distance might evidence a Holy Ghost at work through the existence of the quantum mechanical activities of these TCP and TRP in the inherent presence of Thought force $\left(\mathrm{T}_{\mathrm{F}}\right)$ in vitro and Thought force $\left(\mathrm{T}_{\mathrm{F}}\right)$ in vivo.

It is possible that the quantum enigma can be tackled by accepting the existence of the quantum mechanical activities of these TCP and TRP that are the ultimate constituents of any matter as well as the individual mind. The functional state of mind generates consciousness. This consciousness is acting as an inter-linking agent between the animate and inanimate.

\section{Discussions and Conclusion}

\subsection{Discussions}

All the psychic abilities along with other paranormal phenomena like Extra Sensory Perception (ESP) and Psychokinesis (PK), if true, are to be explained properly by the valid scientific theory. Some critics claim that the existence of psi phenomena would violate "the known laws of physics".

If PK were to exist as claimed by some experimenters, it would violate some well-established laws of physics, including the inverse square law, the second law of thermodynamics and the conservation of momentum indicated by Gardner [37] and Gilovich [38]. Hence scientists have demanded a high standard of evidence for PK, in line with Marcello Truzzi's dictum "Extraordinary claims require extraordinary proof" as mentioned by Sutherland [39]. Parapsychologists respond that "laws of nature" are simply summaries of existing scientific knowledge and do get revised from time to time during the course of scientific progress. If the existence of psi phenomenon were ever proven, explaining how they work might require revising or extending the known laws of physics.

Sagan [40] suggested that there are three claims in the field of parapsychology which have at least some experimental support and "deserve serious study", as they "might be true":

(1) that by thought alone humans can affect random number generators in computers;

(2) that people under mild sensory deprivation can receive thoughts or images "projected" at them;

(3) that young children sometimes report the details of a previous life, which upon checking turn out to be accurate and which they could not have known about in any other way than reincarnation.

Nobel physicist Josephson [41] is one of the more wellknown scientists who say that parapsychological phenomena may be real. Josephson [41] proposed that explanations for both psychokinesis and telepathy might be found in quantum physics. Venkatasubramanian et al [42] investigated paranormal phenomena to show the functional brain imaging of telepathy. Neuroscientist and skeptic Persinger [43] has found evidence suggestive of telepathy based upon quantum entanglement.

The biological nonlocality is possible through the application and utilization of quantum mechanical activities of these TCP and TRP in the inherent presence of Thought force $\left(\mathrm{T}_{\mathrm{F}}\right)$ in vitro and Thought force $\left(\mathrm{T}_{\mathrm{F}}\right)$ in vivo along with the postulated $\mathrm{T}_{\mathrm{F}}$ (micro) and $\mathrm{T}_{\mathrm{F}}$ (macro) as expressed by $\mathrm{Pal}[5]$.

Pal [5] expressed that the thought force $\left(\mathrm{T}_{\mathrm{F}}\right)$ being the primordial quantum field functions as the original single primary unified field that is not only the origin of all the four fundamental fields along with both the $\mathrm{T}_{\mathrm{F}}$ (micro) and $\mathrm{T}_{\mathrm{F}}$ (macro) but also the origin of thought force $\left(\mathrm{T}_{\mathrm{F}}\right)$ in vivo.

Pal [5] expressed that the thought force $\left(\mathrm{T}_{\mathrm{F}}\right)$ in vivo is demonstrated in numerous experiments in which thought has an effect on a physical process (often known as mind over matter). This biological 'thought' is a type of force that can cause movement. Controlling movements through thought alone is observed in several experiments as indicated by $\mathrm{Pal}$ [5]. These experimental observations thus signify the existence of thought force $\left(\mathrm{T}_{\mathrm{F}}\right)$ in vivo.

The scientific community rejects remote viewing due to the absence of an evidence base and the lack of a theory which would explain remote viewing. Some critics in the scientific community reject not only remote viewing but 
also other paranormal phenomena due to the lack of a valid theory which would explain them properly.

All the para-psychological phenomena including psychokinesis and telepathy, if real, can be broadly interpreted through the consciousness model involving the quantum mechanical activities of TCP and TRP in the inherent presence of thought force $\left(\mathrm{T}_{\mathrm{F}}\right)$ in vitro and the thought force $\left(\mathrm{T}_{\mathrm{F}}\right)$ in vivo.

\subsection{Conclusion}

The existence of ESP and PK significantly indicates the existence of these TCP and TRP in the inherent presence of thought force $\left(\mathrm{T}_{\mathrm{F}}\right)$ in vitro and the thought force $\left(\mathrm{T}_{\mathrm{F}}\right)$ in vivo. These TCP, TRP and the thought force $\left(\mathrm{T}_{\mathrm{F}}\right)$ in vitro and thought force $\left(\mathrm{T}_{\mathrm{F}}\right)$ in vivo can exert their roles mentally (internally) as well as physically (externally).

It appears that the standard model of physics is to be correctly tuned by ascertaining the constituents of quarks and leptons in the presence of the unified field in order to explain the functional paranormal power like the Extra Sensory Perception (ESP) and Psychokinesis (PK).

\section{References}

[1] D. Pal and A.U. De, Physics of consciousness and its model may provide guidelines to solve Many scientific problems. Neuroquantology 1: 17-28(2004)

[2] D. Pal and A.U. De, Consciousness model: Significance of thought-carrying particles and thought-retaining particles in quantum measurement as well as cognitive problem. Neuroquantology 2: 115-116 (2005)

[3] D. Pal and A.U. De, The cosmic microwave background radiation temperature signifying the existence of the thought-carrying particle, thought retaining particle and thought force. NeuroQuantology 10: Issue3; 428-442 (September 2012)

[4] M. Bhaumik, Code Name GOD. (Penguin Books India Pvt. Ltd., 11 Community Centre, Panchsheel Park, New Delhi 110017 , India) pp. 132-133; 161-162; 167; 171; 177; 183 and 184. 185-186; 89-190; 198 (2006)

[5] D. Pal, Existence of thought force and its characteristics. American Journal of Modern Physics Vol. 2, No. 6, 2013, pp. 364-374. doi: 10.11648/j.ajmp.20130206.23

[6] V. F. Weisskopf, The Origin of the Universe, The World of Physics, (Simon and Schuster, 1230 Avenue of Americas, New York 10020) 3, pp. 10 and 314 (1987)

[7] D. Pal, Existence of universal consciousness and its characteristics. Accepted for publication in 2014 International Conference on Advanced Education and Management (ICAEM2014) Beijing, China (2013)

[8] I. Prigogine and G. Nicolis, Self-Organization in NonEquilibrium Systems. (Wiley 1977) ISBN 0471024015.

[9] R. Nelson, Director, Global Consciousness Project, Princeton, New Jersey. (2009) rdnelson@princeton.edu
[10] D. Radin, The Conscious Universe: The Scientific Truth of Psychic Phenomena. (Harper Edge) (1997) ISBN 0-06251502-0.

[11] R. Penrose, Shadows of the Mind: A Search for the Missing Science of Consciousness. (Oxford University Press) (1994)

[12] W. Van De Bogart, Earth portals: Exploring New Metaphors of Consciousness 1993 willard@earthportals.com

[13] S. Vivekananda, The Cosmos (the Microcosm). The complete works of Swami Vivekananda. (Advaita Ashrama, India) 2: pp-212 (1989)

[14] S. Parnia, Do reports of consciousness during cardiac arrest hold the key to discovering the nature of consciousness? Medical Hypotheses 69(4): 933-937 (2007)

[15] P van. Lommel, R. Wees, V. Meyers and I. Elfferich, NearDeath Experience in Survivors of Cardiac Arrest: A prospective Study in the Netherlands. The Lancet (9298): 2039-45 (2001)

[16] P. Fenwick, S. Parnia, D.G. Waller, and R. Yeates, A qualitative and quantitative study of the incidence, features and aetiology of near-death experiences in cardiac arrest survivors. Resuscitation 48: 149-156 (2001)

[17] M. Beauregard and D. O'Leary, The spiritual brain: A neuroscientist's case for the existence of the soul. (Harper Collins Publishers) (2008)

[18] M. Beauregard and V. Paquette, Neural correlates of a mystical experience in Carmelite nuns. Neuroscience Letters 405, 186-190 (2006)

[19] D. Radin, The Conscious Universe: The Scientific Truth of Psychic Phenomena. (Harper Edge) (1997) ISBN 0-06251502-0.

[20] R. T. Carroll, "ESP (extrasensory perception)". Skeptic's Dictionary!. Retrieved 2007-06-23.

[21] S. Jeffers, "PEAR Lab Closes, Ending Decades of Psychic Research," Skeptical Inquirer. Amherst, New York, USA. (Committee for Skeptical Inquiry) 31, Issue 3; 16 (May/June 2007)

[22] J. Kakalios, The Physics of Superheores. (New York: Gotham Books/Penguin Group, Inc.) (2005)

[23] H. Genzmer, U. Hellenbrand, "Psychokinesis". Mysteries of the World: Unexplained Wonders and Mysterious Phenomena. (Parragon Books Ltd) (2007)

[24] Time-Life Books. Mind Over Matter (volume of Mysteries of the Unknown encyclopedia series). (Time-Life Books) (1988) ISBN 0-8094-6336-9. OCLC 17877875.

[25] M. R. Hathaway, "Glossary". The Everything Psychic Book. (Adams Media / F+W Publications Company) (2003) ISBN 1-58062-969-5.

[26] FC. Mish, "Teleportation. The act or process of moving an object or person by psychokinesis." (Merriam-Webster Incorporated) (2004) ISBN 0-87779-809-5. OCLC 146761465.

[27] A M. Colman, "Psychokinesis. The movement or change of physical objects by mental processes" Dictionary of Psychology. (Oxford University Press) (2001) ISBN 0-19866211-4. 
[28] R. Cavendish and B. Innes, Man, Myth \& Magic: The Illustrated Encyclopedia of Mythology, Religion, and the Unknown. (New York: Marshall Cavendish Corporation) (1995) ISBN 1-85435-731-X. OCLC 228665658.

[29] Mass Media Funk, The Skeptic's Dictionary. http://skepdic.com/refuge/funk3.html. (Retrieved February $27,2007)$

[30] F. Bersani and A. Martelli, Psychoenergetics: The Journal of Psychophysical Systems. (United Kingdom: Gordon and Breach Science Publishers) 99-128 (1983)

[31] E. McCoy, Astral Projection for beginners.Minnesota: (Llewllyn Publications) 207. (2006) ISBN 1-56718-625-4.

[32] E. Davis, U.S. Air Force Research Laboratory. "Teleportation Physics Study" http://www.fas.org/sgp/eprint/teleport.pdf.

[33] R E. Guiley, Encyclopedia of the Strange, Mystical \& Unexplained. (New York: Gramercy Books) (1991) ISBN 0517-16278-4.

[34] R S. Broughton, Parapsychology: The Controversial Science. (New York: Ballantine Books) (1991) ISBN 0-345-356381.

[35] R. Hyman, "The Ganzfeld Psi Experiments: A Critical Appraisal". Journal of Parapsychology 49 (985)
[36] D. Radin, The Conscious Universe: The Scientific Truth of Psychic Phenomena. (Harper Edge) (1997) ISBN 0-06251502-0.

[37] M. Gardner, "Einstein and ESP". In Kendrick Frazier. Paranormal Borderlands of Science. (Prometheus) (1981) ISBN 0-87975-148-7.

[38] T. Gilovich, How We Know What Isn't So: The fallibility of human reason in everyday life. (Simon \& Schuster) (1993) ISBN 0029117062.

[39] S. Sutherland, Irrationality: the enemy within. (Penguin books) (1994) ISBN 0-14-016726-9. [40] C. Sagan, The Demon-Haunted World, (Random House) p. 302 (1997)

[40] C. Sagan, The Demon-Haunted World, (Random House) p. 302 (1997)

[41] BD. Josephson, Biological Utilization of Quantum Nonlocality. Foundations of Physics. 21; 197- 207 (1991)

[42] G. Venkatasubramanian, Investigating paranormal phenomena: Functional brain imaging of telepathy. International Journal of Yoga 1:2 (2008)

[43] MA. Persinger et al., The Electromagnetic Induction of Mystical and Altered States Within the Laboratory. Journal of Consciousness Exploration \& Research 1 (7): 808-830 (2010) ISSN 2135-8212. 